\title{
Prepared Environment as the Key Success Factor in Building Clean and Healthy Habit in Early Childhood Education
}

\author{
Ni Luh Sekar Astuti ${ }^{1 *}$, Lidia Sandra ${ }^{1}$ \\ ${ }^{1}$ Universitas Kristen Krida Wacana, Indonesia \\ "Corresponding author.Email: sekarastuti@cendekiaharapan.sch.id
}

\begin{abstract}
Prepared environment fosters children's independence according to their developmental stage. Maria Montessori's idea related to the preparation of learning environment is everything that interacts or relates to students will facilitate and maximize their independence of learning and exploration of knowledge. This research aims to create a model for building clean and healthy habit formation, and to find out the most significant factors to influence a habit. The research method used were mixed method: qualitative method and quantitative method. Qualitative method was used in order to get the empirical data using interview and observation to all stakeholders, and quantitative method was used in order to examine the model using SEM Analysis. The result is that prepared environment encourages love of learning, independence, exploration and experiments among children. Prepared environment is an environment that prepares students to think and act freely, remains in structure and a certain setting, an environment that is highly committed to beauty and decency, an environment that is socially friendly and stimulates intellectual abilities are the automatic entry points in forming healthy habits and innovative culture through the mediation of love of learning, independence, experiment and exploration variables.
\end{abstract}

Keywords: Prepared Environment, Maria Montessori, Clean and Healthy Habit

\section{INTRODUCTION}

Health is one of the main assets in national growth and life. School as the main place in the development of cognitive, affective and psychomotor also plays a role in improving the health standard of the nation. Therefore, the school health is needed to improve students' ability to live healthily so that students can learn, grow, and develop harmoniously and optimally. The realization of a healthy school would have a positive impact as an effort to improve the quality of education and student's learning achievement so as to enable student's growth and development in accordance with the child's developmental stage in an effort to form a complete human being. This is supported by research conducted by Kalimatusyaro which showed that the health of students has a significant effect on student achievement [1].

In the realization of a healthy school, the practice of clean and healthy living plays a central role. Therefore, it is aimed to create a clean and healthy environment, promote effective teaching and learning, and improve the health standard of all school members and the surrounding community. However, the practice of clean and healthy living cannot be formed instantly. The formation of it begins when children are born and grow in their family environment. This cannot be separated from the family economic status. On the one hand, the economic background of the family provides opportunities for children to have more convenience to get health services and facilities needed for various purposes including learning. However, at the same time it also poses considerable challenges related to parenting and child development. This is inseparable from the significant relationship between the socio-cultural background of students and the implementation of clean and healthy living behaviors in students' daily lives [2].

What it means by this parenting style is the tendency to spoil the child by providing extra assistance and excessive facilities so that it does not stimulate the child's natural sensorial abilities that should have been developed from an early age. For example, giving and or using the device excessively; and providing assistants or housemaids. Such parenting has great potential to be the cause of the inhibition of children's psychosocial, 
emotional development and especially sensorial development, which are the basic assets for children's intellectual preparation and literacy readiness at primary age. This is supported by the results of Vinayastri's study which showed that early intervention on brain development is more influential than intervention in adulthood because brain development occurs rapidly at the age of 0-6 years [3]. Challenges related to parenting and child development can be resolved through the normalization of children in the educational process at school. According to Maria Montessori, the normalization process occurs when children are given the freedom to interact with the environment according to their wishes. The position of the teacher or adult in the process of normalizing children is not a source of information [4]. The role of the teacher is actually important in maintaining the learning environment in accordance with the order to provide facilities or freedom for students to learn and develop their full potential. Likewise, in developing the practice of clean and healthy living. The results of Kurniyanti's research also showed that classroom teachers have a role as role models that have a significant effect on the awareness of clean and healthy life for students [5].

According to Maria Montessori, preparing a learning environment in the process of normalizing children needs to pay attention on six aspects or principles, namely freedom, structure and order, beauty, nature and reality, social environment, and intellectual environment [6]. Therefore, in the formation of the practice of clean and healthy living in early childhood education, it is necessary to further examine: How can clean and healthy living habits be formed through a prepared environment? What are the factors that most influence the formation of this practice? This research was conducted to formulate a model for the formation of clean and healthy habits in early childhood education and to analyze what factors have the most influence on the formation of these habits.

\section{THEORETICAL FRAMEWORK}

According to Maria Montessori, education aims to stimulate children's thinking with structured activities so that they are able to respect themselves and the environment around them through a process of normalization. The normalization process occurs when children are given the freedom to interact with the environment as they wish. If the normalization process goes well, children would have very full concentration on the work done with the tools they choose themselves in the Montessori room so that the desire for peace and discipline would develop in the child [6].

Normal children are children who are full of joy and harmony. Montessori has the belief that only the child can lead himself/herself to become a normal child. Normal children have several characteristics, including: (1) love of order; (2) love of work; (3) profound spontaneous and concentration; (4) attachment to reality; (5) sublimation of the possessive instinct; (6) power to act from real choice; (7) independence and initiative; (8) spontaneous self-discipline; and (9) joy [6].

The teacher only acts as a facilitator, which does very little teaching and observes a lot of child development. The teacher is in charge of directing students to find the best method of learning from their environment. The teacher acts like a catalyst that accelerates the learning process in students, without participating in the learning process, but only helps students to interact with their learning environment. The teacher only presents how to use Montessori tools without talking much and makes sure the child pays attention to the stage by stage of the presentation he is doing to develop a soul of discovery in the child.

Teachers are not the most important role in learning, even Montessori said that "the children are now working as if I did not exist", children should work independently as if there were no teachers. This happens because basically the purpose of education is to liberate children so that they are not dependent on other people or possessive of someone or objects. The role of the teacher is actually important in maintaining the learning environment in accordance with the order to provide facilities or freedom for students to learn and develop their full potential. The promise of Montessori is simple, children learn in a unique way distinct from the adults. Instructors should not ignore the absorbent mind of these unique individuals. Educators cannot attempt to flout the importance of sensory learning as an effective and efficient means of educating their young [7]. Children will feel satisfied with the discovery process they are doing because they are given the freedom to choose and carry out their activities, such as the Montessori education slogan "help me to do it by myself".

As previously explained, the most important role of the teacher in learning is to prepare a child's learning environment in accordance with the principles of Montessori education. According to Montessori, "the first aim of the prepared environment is, as far as it is possible, to render the growing child independent of the adult." Montessori's thinking related to the preparation of a learning environment is that everything that interacts or relates to students will facilitate and maximize learning independence and knowledge exploration with themselves. In general, there are six aspects or principles in preparing the learning environment, namely freedom, structure and order, beauty, nature and reality, social environment, and intellectual environment [8].

Freedom, the aspect of freedom in the preparation of a learning environment must give children freedom to move, freedom to explore, freedom to interact, freedom from interference from others, and freedom to choose. This needs to be done because Montessori education believes children should be free to explore and still 
follow their natural desire to develop their potential and increase knowledge about the world around them. The children are given the option to explore the learning environment, choose the material they would like to learn, and may complete and opt the repeat said activity as much as they'd like. This allows the child to not only express their innate desire to learn, but also develop a level of self-confidence and self-efficacy in understanding the learning material [9].

Structure and order, structure and order would accurately increase understanding of the structure and order of the universe. Children would begin to internalize the order around them, and make an understanding of the world in which they live. The child would become accustomed to returning the tools he/she uses to his order so that his/her natural desire for structure and order would increase. Therefore, all equipment used to support the learning process of students is prepared according to the size of the child sized, and children are instructed in its care and in skills for moving and carrying it. All children should feel that they are in control of this aspect of their environment and that they are competent to manipulate materials that are, in most classrooms, too bulky or heavy for them to handle [10].

Beauty, the beauty in the Montessori learning environment is important because the learning environment must be able to give a simple sense of harmony in the child. All objects are neat, in order and well-maintained to show peace and tranquillity for students. The learning environment must also attract students to come and work well to increase student's interest in learning, as well as provide an atmosphere that is easily seen and train attitudes in working between children and adults. Children are attracted to the beauty of the environment and learn to protect and restore that beauty as part of their daily routines [11]

Nature and reality, nature and reality are indeed the hallmarks of the Montessori learning environment. Children learn from the concrete to the abstract, so they must be given real and natural things in the learning process [12]. Recognition of real and natural things is very important because it is the visual of the object that he/she will use in constructing his/her present and future understanding so that it is very influential for the child's life. Misconceptions of objects will cause children's misconceptions about the objects they are learning. Therefore, the teacher must be able to prepare an environment that is truly natural and real so that the child does not experience misconceptions and is able to distinguish fantasy from reality.

Social environment, the social environment will provide opportunities for children to have a sense of empathy and compassion for others. Social interaction in learning activities would support children's social and emotional development to become caring children and prepare them for the world of work, and to play in a group. The social environment could be implemented by creating mixed-age classes so that children could interact with their younger siblings or older siblings, and their peers. Therefore, the children can work collaboratively, interact with peers, and find their place in the social community [13].

Intellectual environment, an educational environment that is prepared to develop the child's individual not only intelligence [14]. This environment is realized by guiding children to learn the five Montessori areas, namely sensorial, practical life, mathematics, language, and culture. It aims to prepare children for the next level of education which requires basic concepts that students really have to understand. A foundation must be strong so that the house can stand firm. Therefore, the basic concepts must be developed properly in kindergarten so that later children do not experience difficulties in understanding the material in primary, secondary and advanced, and even universities.

\section{RESEARCH METHOD}

This research is a descriptive study with a mixedmethod. Qualitative data were collected through interviews and observations to all stakeholders at Cendekia Harapan School. Furthermore, quantitative data were obtained through testing a model for the formation of a clean and healthy living culture through SEM analysis. This study uses an SEM approach because SEM is able to explain complex relationships between variables, and test relatively complex series of relationships better [15]. The formulation of the model for the formation of a clean and healthy living practice in this study was carried out in several steps in accordance with the SEM approach, namely; (1) theory-based model development; (2) development of flowcharts; (3) model specifications; (4) model identification; (5) parameter estimation; (6) fit model assessment; (7) model modification; and (8) cross validation of the model. The fit model assessment was conducted to test the suitability of the theoretical model with empirical data using the Linear Structural Relationship (LISREL) tool. This is because LISREL can be easily used to determine the causes of a model not being fit or a poor model, making it easier for researchers to modify the model. Steps seven and eight are only carried out when the results of the model assessment are not fit so that substantial modifications to the model are required. LISREL can be easily used to find out the causes of a model not fit or a bad model, making it easier for researchers to modify the model.

\section{RESULT AND DISCUSSION}

Theoretically, according to Maria Montessori, there are six aspects or principles in a prepared environment, namely freedom, structure and order, beauty, nature and 
reality, social environment, and intellectual environment. This is supported by the results of empirical data collection through interviews and observations which showed that: (1) a prepared environment has been implemented with reference to its six principles, namely freedom, structure and order, beauty, nature and reality, social environment, and intellectual environment. ; (2) prepared environment is the key to the success of health promotion for early childhood; and (3) the formation of the practice of clean and healthy living, as well as the practice of innovation through a prepared environment mediated by the love of learning, independence, and experimentation and exploration of students [14]. In the
SEM approach, the variables found above are then grouped into two, namely exogenous variables (independent variables) and endogenous variables (dependent variables and mediating variables). After going through SEM analysis, it was found that prepared environment became the independent variables, practice of healthy living and innovation became dependent variables, and love of learning, independent, and experiment \& exploration became the mediating variables. The visualization of the model for the formation of a clean and healthy living practice can be seen in Figure 1 below.

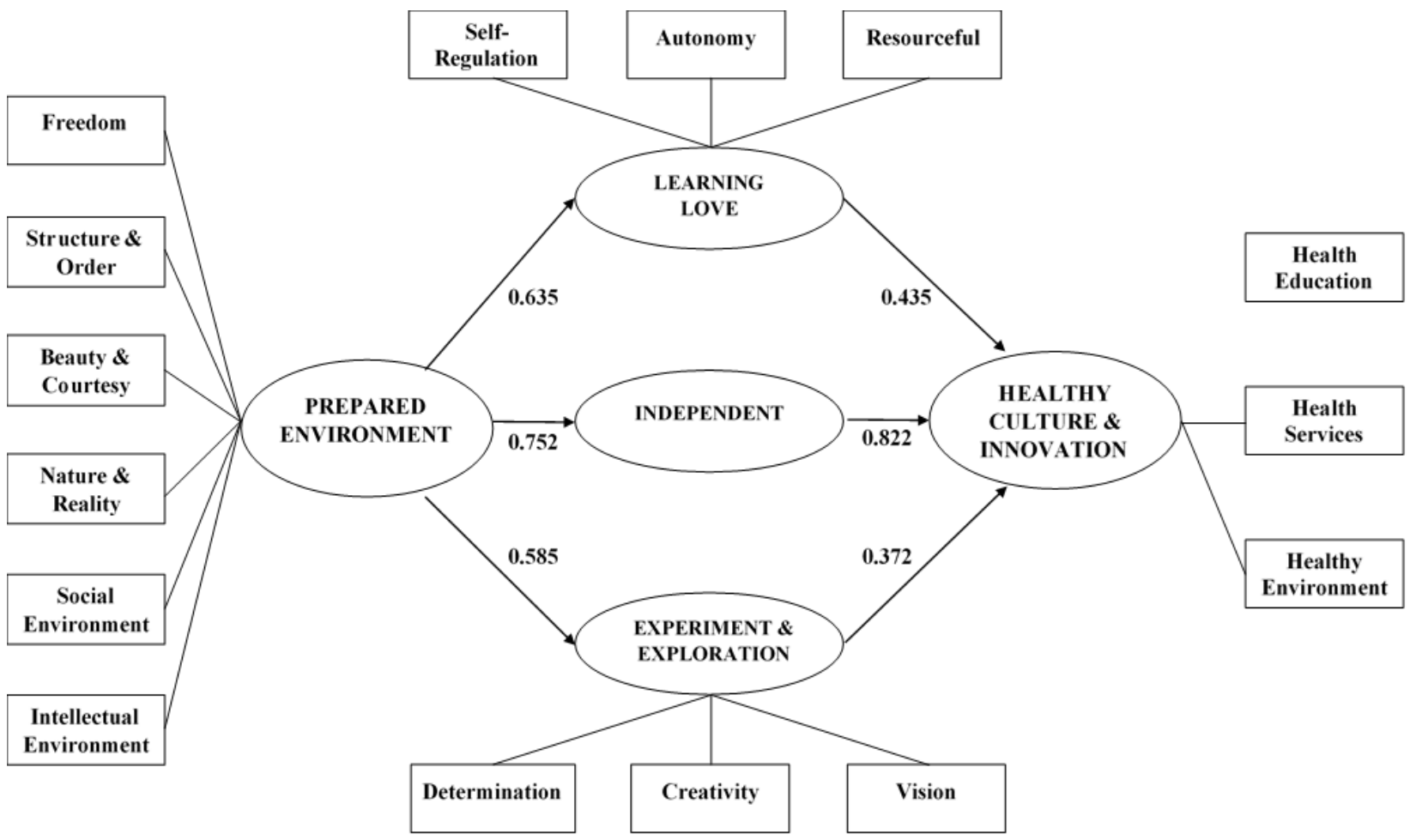

Figure 1. The Model for Forming a Clean and Healthy Living Culture

Based on the visualization of the model for forming a clean and healthy living practice above, the significant regression lines from the Prepared Environment to Healthy Culture and Innovation are as follows:

a. Prepared Environment (PE) for Love of Learning (LL) with an estimated loading factor value of 0.635 and a $\mathrm{t}$-value of 20,516 with an error variance of $0.0432(\mathrm{H} 3)$.

b. Prepared Environment (PE) on Independence (IND) with an estimated loading factor value of 0.752 and a t-value of 2.785 with an error variance of 0.0318 (H4).

c. Prepared Environment (PE) for Experiment and Exploration (EE) with an estimated loading factor value of 0.585 and a t-value of 2.592 with an error variance of 0.0303 (H5). d. Love of Learning (LL) towards a healthy culture and innovation (SI) with an estimated loading factor value of 0.435 and a t-value of 21.154 with an error variance of $0.0428(\mathrm{H} 7)$.

e. Independence (IND) towards a healthy culture and innovation (SI) with an estimated loading factor value of 0.822 and a t-value of 6,907 with an error variance of $0.0338(\mathrm{H} 8)$

f. Experiment and Exploration (EE) on healthy culture and innovation (SI) with an estimated loading factor value of 0.372 and a t-value of 6,515 with an error variance of 0.0309 (H9).

The results above indicate that the formation of healthy culture and innovation is most significantly influenced by children's independence. This is a crystallization of the implementation of a prepared environment that significantly forms independence in 
early childhood students. Empirically, healthy culture and innovation is also formed from the love of learning, experimentation and exploration in young students who are encouraged by the implementation of prepared environments.

The love of learning, independence, experimentation and exploration were found to be successfully formed through the learning process or normalization of students through a prepared environment. This is in line with Maria Montessori's thinking that children will learn well if the environment is appropriate in size to stimulate and make it easier for children to be able to absorb their cognitive thoughts in the environment. Montessori also emphasized that education requires a good environment to develop the potentials that the child has brought from birth, in an educational environment it will not be separated from the characteristics of the child and the stage of development [16].

The prepared environment is a venue for developing social and moral skills of children, especially in terms of order, cleanliness, grace, and courtesy. Returning materials to the correct places and keeping shelves from dusted, and to make things tidy are simple tasks that develop habits that contribute to moral development. The act or caring for plants and class pets contributes to the child's sense of responsibility and compassion for life [16]. The moral values that are implanted through this prepared environment will then form a culture of clean and healthy living independently by students.

This is where the prepared environment seems to support the implementation of early childhood education in accordance with the stages of child development. Because, each child will absorb information or knowledge through direct interaction between the child and his/her learning environment, then enter their minds, become part of the child's self, experience and conceptual network [17]. This concept has been empirically proven to form a healthy culture and innovation for children. Children can freely explore the essence of clean and healthy living through a prepared environment so that they are able to independently live clean and healthy lives. This independence then forms a habit or culture to live cleanly and healthily wherever the child is. Even, children would feel uncomfortable if the clean and healthy lifestyle is not done for some reason.

It is interesting to see how prepared environment can be a key to the success of health promotion in early childhood. Through appreciation of the prepared environment and the normalization process, teachers can understand the nature of education for early childhood. Teachers believe education is carried out to humanize humans to become whole, so that teachers as facilitators at Cendekia Harapan School are willing to organize and care for the learning environment independently because only the teachers understand the development of their students, not other people (messengers) so that the children's learning environment is appropriate with the need to support the development of the potential in them. Not only by involving teachers, prepared environment can also be realized through a good collaboration among all school stakeholders, as well as the guests that come to school by taking care of prepared environment cooperatively.

\section{CONCLUSION}

The model for forming a clean and healthy living culture showed that prepared environment is the key to the success of health promotion in early childhood education. Prepared Environment is an environment that prepares students to think and act freely, remains in structure and a certain setting, an environment that is highly committed to beauty and decency, an environment that is socially friendly and stimulates intellectual abilities are the automatic entry points in forming a healthy habits and innovative culture through the mediation of love of learning, independence, experiment and exploration variables. The environment shapes human behaviour and therefore produces culture.

\section{REFERENCES}

[1] M. Kalimatusyaro, The Effect of Mental Health, Learning Motivation and Discipline Learning Against Student Achievement, Postgraduate Sunan Ampel State Islamic University: Surabaya, 2018.

[2] R. R. Lestari, Socio-Cultural Relationships and the Role of Teachers on the Low Implementation of PHBS, Prepotif Journal of Public Health 2(1) (2018) 37-47.

[3] A. Vinayastri, The Effect of Parenting on Early Childhood Brain Development, Widya Scientific Journal 3(1) (2015) 33-42.

[4] M. Montessori, The Absorbent Mind, Osmania University: The Theosophical Publishing House, 1949.

[5] M. A. Kurnayanti, The Effect of Homeroom Teacher Role Model on Increasing Students Awareness of Clean Healthy Living Behavior, Husada Media Health Scientific Journal 9(2) (2020) 100-104.

[6] M. Montessori, The Montessori Method: A Compulsory Guide for Early Childhood Education Early Childhood Teachers and Parents, Yogyakarta: Student Library, 2013.

[7] Q. Faryadi, The Montessori Paradigm of Learning: So What?, 2007, pp. 1-17. Retrieved from https://eric.ed.gov/?id=ED496081 
[8] M. Montessori, The Absorbent Mind: The Absorbent Mind, Yogyakarta: Student Library, 2008.

[9] L. B. Johnson, A Developmental Psychological Analysis of a Montessori Environment, 2019. Retrieved from https://www.researchgate.net/publication/3335069 26

[10] L. K. Suzanne, Affective and social development: some ideas from Montessori's prepared environment, Topics in Early Childhood Special Education, 1982, pp. 55-62.

[11] Cain, R., Moral Development in Montessori Environments, Montesori Life, 17(1), (2015), pp.18-20.

[12] R. O. G. Moreno, M. Reisslein, Teaching with concrete and abstract visual representations: Effects on students' problem solving, problem representations, and learning perceptions, Journal of Educational Psychology, 103(1) (2019) 32-47.

[13] I. Navara, Benefits and Challenges of Mixed-age Classrooms for Small Schools: the Montessori Approach to Early Childhood Education, The Journal Scuola Democratica, 1, 2019, pp. 334-338.

[14] M. Montessori, The Absorbent Mind: The Absorbent Mind, Yogyakarta: Student Library, 2008.

[15] I. Ghozali, Fuad, Structural Equation Modeling: Theory, Concepts, and Applications with LISREL 8.50 Program, Semarang: Diponegoro University Publishing Agency, 2005.

[16] R. Cain, Moral Development in Montessori Environments, Montesori Life 17(1) (2015) 18-20.

[17] M. Montessori, The Montessori Method: A Compulsory Guide for Early Childhood Education Early Childhood Teachers and Parents, Yogyakarta: Student Library, 2013. 